\title{
Increase of urinary malondialdehyde level by bisphenol A exposure: a longitudinal panel study
}

\author{
Jin Hee Kim ${ }^{1 *}$ and Yun-Chul Hong ${ }^{2,3}$
}

\begin{abstract}
Background: To verify oxidative stress as a possible mechanism that establishes a relationship between exposure to bisphenol A (BPA) and adverse health outcomes in the elderly Korean population, we evaluated the relation between visit-to-visit variations in urinary BPA and oxidative stress biomarker.

Methods: To assess the relation between BPA and urinary malondialdehyde (MDA) as an oxidative stress biomarker, we used a mixed effect model after controlling for age, sex, BMl, drinking status, exercise, urinary cotinine level, $\mathrm{PM}_{10}$ on lag day 2, and mean temperature and dew point on the day. The relation between exposure to BPA and MDA level by sex of participants and polymorphisms of oxidative stress-related genes (COX2, EPHX1, HSP70-hom, PON1, eNOS, CAT, DRD2, SOD2, and MPO) was also evaluated.

Results: A significant association was found for BPA with MDA in both male and female elderly participants (male, $\beta=0.19$ and $p=0.0003$; female, $\beta=0.18$ and $p<.0001$; and total, $\beta=0.18$ and $p<.0001$ ). Furthermore, the association of BPA with MDA was found regardless of any genotype of the nine oxidative stress-related genes.

Conclusions: The results of our study suggest a strong association of BPA with oxidative stress, not related with sex and oxidative stress-related gene polymorphisms.
\end{abstract}

Keywords: Elderly, Bisphenol A, Oxidative stress, Malondialdehyde

\section{Background}

Bisphenol A (BPA) is a chemical with highest levels of production worldwide, with an annual increase of 6 to $10 \%$ [1]. The ubiquitous exposure to BPA [1] and its toxic potential [2-4] raise concerns of its adverse effects on both non-sexual and sexual organs [5-7]. Recently, several studies have suggested that oxidative stress is a possible mechanism that establishes the relation between exposure to BPA and adverse health outcomes [8, 9]. However, there has been a limited number of reports on the relation between BPA exposure and oxidative stress biomarkers [10-17], particularly for malondialdehyde (MDA) $[10-13,16]$. Moreover, in previous studies, it has

\footnotetext{
* Correspondence: jhkim777@sejong.ac.kr

1 Department of Integrative Bioscience \& Biotechnology, Sejong University,

209 Neungdong-ro, Gwangjin-gu, Seoul, Republic of Korea

Full list of author information is available at the end of the article
}

been difficult to capture within-subject changes because of their cross-sectional nature of the associations $[10-13,16]$. For this reason, a longitudinal study with repeated measurements is required to account for within-subject changes in BPA exposure and oxidative stress levels since each subject in the panel study can be used as his or her own control with repeated measurements of rapidly changing covariates.

Therefore, in the present study, we repeatedly measured the urinary levels of BPA and MDA as a lipid peroxidation marker in the Korean elderly population, and estimated acute effect of BPA on MDA level. Furthermore, we also estimated the effect of BPA on MDA level by sex of participants and polymorphisms of oxidative stress-related genes (COX2, EPHX1, HSP70-hom, PON1, eNOS, CAT, DRD2, $S O D 2$, and $M P O)$. 


\section{Methods}

\section{Study population and sampling}

This study estimated the relation between BPA exposure and urinary levels of MDA, an oxidative stress biomarker, in the elderly aged 60 or over recruited from the Korean Elderly Environmental Panel (KEEP) study. Briefly, among a total of 560 elderly people who visited a community elderly welfare center as many as five times for a medical examination (twice in 2008, once in 2009, and twice in 2010) [9], 548 subjects were included in the analysis after excluding 12 whose blood samples were unavailable.

\section{BPA measurement}

We measured urinary levels of total BPA, including free and conjugated BPA, using HPLC tandem mass spectrometry (HPLC: Agilent 1200, USA; MS/MS: Agilent 6410 Triple Quad LCMS, Agilent, USA) according to previously reported procedures [9]. Shortly, five-hundred microliters of urine were buffered with $30 \mu \mathrm{L}$ of $2.0 \mathrm{M}$ sodium acetate $(\mathrm{pH}$ 5.0) and were then spiked with $25 \mu \mathrm{L}$ internal standard BPA (RING-13C12, 99\%; Cambridge Isotope Lab, Inc., Andover, MA, USA) and $10 \mu \mathrm{L}$ ( $\geq 900$ units) of glucuronidase/sulfatase (Sigma-Aldrich G7770, St. Louis, MO, USA). The accuracy, coefficient of precision variation, and coefficient of reproducibility variation were 99.7\%, 1.0-4.7, and 0.5-5.3, respectively, based on the quality control method adopted from the Clinical and Laboratory Standards Institute (CLSI) guidelines. The limit of detection (LOD) of urinary BPA was $0.01 \mu \mathrm{g} / \mathrm{L}$.

\section{MDA measurement}

We measured urinary levels of MDA as an oxidative stress biomarker. Urinary MDA levels were determined by measuring thiobarbituric acid reactive substances [18]. Shortly, $50 \mu \mathrm{l}$ of urine were mixed with $300 \mu \mathrm{l}$ of $0.5 \mathrm{M}$ phosphoric acid solution and $150 \mu \mathrm{l}$ of $23 \mathrm{mM}$ TBA solution (Sigma-Aldrich T-5500, Steinheim, Germany) and were heated at $95{ }^{\circ} \mathrm{C}$ for $1 \mathrm{~h}$. After cooling on ice, the mixture was vortexed with $500 \mu \mathrm{l}$ of methanol and was centrifuged at 5000 $\times \mathrm{g}$. The absorbance of the supernatant was measured at $532 \mathrm{~nm}$ using HPLC-UV with a mobile phase of potassium phosphate $(0.05 \mathrm{~mol} / \mathrm{L} ; \mathrm{pH} 6.8)$ and methanol $(58: 42, v / v)$.

\section{Cotinine measurement}

Urinary cotinine levels were measured to monitor tobacco exposure. The cotinine level was analyzed using an enzyme-linked immunosorbent assay [18].
Particulate matter less than $10 \mu \mathrm{m}\left(\mathrm{PM}_{10}\right)$ concentration and meteorological factors

In a previous study for the delayed effects of $\mathrm{PM}_{10}$ on MDA level, significant associations of $\mathrm{PM}_{10}$ on lag day 2 and outdoor temperature and dew point on the day with MDA level were found [18] and thus we adjusted for these factors in our models. Data was acquired from the Korea National Institute of Environmental Research for $\mathrm{PM}_{10}$ on lag day 2 at the monitoring center nearest to the residence of each participant [18]. The outdoor temperature and dew point measured at the Songwoldong monitoring center nearest to the residence of the study participants during the study period were obtained from the Korea Meteorological Administration [18].

\section{Genotyping of oxidative stress-related genes}

Genomic DNA was extracted from peripheral blood lymphocytes using a QIAamp DNA Blood Mini Kit (Qiagen, Valencia, CA, USA), and twenty-one polymorphisms of nine oxidative stress-related genes - cyclooxygenase 2 (COX2), epoxidehydrolase 1 (EPHX1), heat shock protein 70-hom (HSP70-hom), paraoxonase 1 (PON1), endothelial nitric oxide synthase (eNOS), catalase $(C A T)$, dopamine receptor D2 (DRD2), superoxide dismutase 2 (SOD2), and myeloperoxidase (MPO) were determined using the TaqMan fluorogenic 5' nuclease assay (rs5277 for COX2, rs3766934, rs1051740, and rs2234922 for EPHX1, rs2227956 and rs2075800 for HSP70-hom, rs854560, rs13306698, and rs662 for PON1, rs1799983 for eNOS, rs769218 and rs769217 for CAT, rs1800497 for DRD2, rs4880, rs2758331, and rs5746136 for SOD2, and rs7208693 for MPO) and a single base primer extension assay (rs3218625 for COX2, rs2853796 and rs7830 for eNOS, and rs2071409 for MPO). Negative controls were included to ensure genotyping accuracy. For confirmation, five percent of the samples were randomly chosen and genotyped again, producing identical results.

For the TaqMan fluorogenic 5' nuclease assay (ABI, Foster City, CA, USA), the final volume of polymerase chain reaction (PCR) was $5 \mu \mathrm{l}$, containing $10 \mathrm{ng}$ of genomic DNA and $2.5 \mu \mathrm{l}$ TaqMan Universal PCR Master Mix, with $0.25 \mu \mathrm{l}$ of $20 \mathrm{X}$ or $0.125 \mu \mathrm{l}$ of $40 \mathrm{X}$ Assay Mix (Assay ID, AHVI68H for rs5277, C__2725995_20 for rs3766934, C__14938_30 for rs1051740, C_11638783_30 for rs2234922, C_25630755_10 for rs2227956, C__3052613_1_ for rs2075800, АНТ9819 for rs854560, C_31373257_10 for rs13306698, C_2548962_20 for rs662, C__3219460_20 for rs1799983, C__3102900_10 for rs769218, C__3102907_10 for rs769217, C__7486676_10 for rs1800497, C__8709053_10 for rs4880, C_16288770_10 for rs2758331, C_29322854_10 for rs5746136, and C_25609936_10 for rs7208693). All 
polymerase chain reactions and endpoint fluorescent readings were conducted according to previously reported procedures [9]. For the single base primer extension assay, SNaPShot assay kit (ABI, Foster City, CA, USA) was used according to previously reported procedures [9].

The primers and probes designed for rs5277, rs3218625, rs854560, rs2853796, rs7830, and rs2071409 were as follows:

rs5277-forward, 5' -TCCCTTCCTTCGAAATGCAAT TATGA-3' ,

rs5277-reverse, $5^{\prime}$-GCTAAAAACCTTAGAAAGACA CTTGT-3' ,

rs5277-VIC, 5' -CTTACATGTCAACACATAAC-3' , rs5277-FAM, 5' -ACATGTCAAGACATAAC-3' , rs3218625-forward, 5' -ATTCAGTGTTCCAGATCCA GAG-3' ,

rs3218625-reverse, $5^{\prime}$-AAATAAATATGATCATTAG ACTTCTACAGTTC-3' ,

rs3218625-SNP, 5' -CATCAATGCAAGTTCTTCCCG MTCC-3' ,

rs854560-forward, 5' -ACAACCTGTACTTTCTGTT CTCTTTTCTG-3' ,

rs854560-reverse, 5' -GAAAACACTCACAGAGCTA ATGAAAGC-3' ,

rs854560-VIC, 5' -CAGTATCTCCAAGTCTTC-3' , rs854560-FAM, 5' -CAGTATCTCCATGTCTTC-3' , rs2853796-forward, 5' -TTCCTGTSCCAGAGGC

AG-3' ,

rs2853796-reverse, 5' -GACAAGGTTGTCACAGG

GC-3' ,

rs2853796-SNP, 5' - CCYTGAAGCCGTCCCTGGGG CTGGG-3' ,

rs7830-forward, 5' - ATTCTGGCAGGAGCGGCT-3' , rs7830-reverse, 5' -TCTGTCCCTAGATTGTGTGA CTC-3' ,

rs7830-SNP, 5' -ACTCCCTTCAGGCAGTCCTTTAG TC-3' ,

rs2071409-forward, 5' - TGCCAGCCCAGAATAT

CC-3'

rs2071409-reverse, 5' -GCTGCATGCTGAACAC

AC-3' ,

rs2071409-SNP, 5' -CACAGTGTCCATGGGTGTTC CCC-3' .

The probes for rs1051740, rs2234922, rs13306698, and rs662 were DME, and those for rs3766934, rs2227956, rs2075800, rs1799983, rs769218, rs769217, rs1800497, rs4880, rs2758331, rs5746136, and rs7208693 were predesigned.

\section{Statistical analysis}

The BPA concentrations under the LOD were assigned as a default value of LOD concentration divided by 2 .
Since the detection range for cotinine was 1$10,000 \mathrm{mg} / \mathrm{L}$, the cotinine level was assigned as $0.5 \mathrm{mg} / \mathrm{L}$ for values less than $1 \mathrm{mg} / \mathrm{L}$ and $15,000 \mathrm{mg} /$ $\mathrm{L}$ for values greater than $10,000 \mathrm{mg} / \mathrm{L}$. Because the present panel study conducted repeated measurements of urinary BPA and MDA at several time points for each individual (five measurements at maximum for both exposure and outcome), we used a mixed effect model with repeated values of BPA and MDA levels to assess the relation of visit-to-visit variations in BPA exposure with MDA levels in order to evaluate the short-term effects of the changes in BPA exposure levels over time. In the model, we adjusted for age, sex, body mass index (BMI), drinking status, exercise, urinary cotinine level, $\mathrm{PM}_{10}$ on lag day 2, and mean temperature and dew point on the day because these factors affected the MDA level significantly. Age, BMI (weight $(\mathrm{kg}) /$ height $^{2}\left(\mathrm{~m}^{2}\right)$ ), cotinine levels, $\mathrm{PM}_{10}$ on lag day 2 , and mean temperature and dew point on the day were treated as continuous variables, and sex, drinking status, and exercise were treated as categorical variables in the models. We also estimated the relation between BPA and MDA levels by sex and by the genetic polymorphisms of COX2, EPHX1, HSP70-hom, PON1, eNOS, CAT, DRD2, $S O D 2$, and $M P O$. Furthermore, we calculated intraclass correlation coefficients (ICCs) - defined as the ratio of inter-individual variance to total variance - of BPA and MDA to evaluate the intra- and interindividual variations of repeated BPA and MDA measures. SAS version 9.3 (SAS Institute Inc., Cary, NC, USA) was used for statistical analyses with a significance level of $p<0.05$.

\section{Results}

The participants in our study were a total of 548 elderly people, 142 males and 406 females (Table 1). At baseline, the mean age of the participants was 70.8 years, and the number of obese participants with $\mathrm{BMI} \geq 25$ was 242 (44.2\%). Current smokers, drinkers, and exercisers were $5.5,22.1$, and $61.5 \%$, respectively, and male participants smoked and consumed alcohol more than female participants (both $p<.0001$ ). The mean number of visits of the participants was 3.3 , and females participated more actively compared to males $(p=0.0847)$.

BPA, MDA, and cotinine were measured in a total of 1625, 1637, and 1632 urine samples, respectively (Table 2). The mean levels (inter-quartile ranges) of urinary BPA, MDA, and cotinine were $1.2 \mu \mathrm{g} / \mathrm{L}(0.4-$ $1.2 \mu \mathrm{g} / \mathrm{L}), 1.9 \mu \mathrm{mol} / \mathrm{L}(1.1-2.4 \mu \mathrm{mol} / \mathrm{L})$, and $274.7 \mathrm{mg} / \mathrm{L}$ (0.5-4.5 mg/L), respectively. In particular, 95 percentile and maximum levels of urinary BPA were $3.7 \mu \mathrm{g} / \mathrm{L}$ and $67.6 \mu \mathrm{g} / \mathrm{L}$, respectively, and number of urine samples with BPA concentrations under the LOD was 32 . In the 
Table 1 Demographic characteristics of the participants

\begin{tabular}{|c|c|c|c|c|}
\hline Characteristic & Total & Male & Female & $p$-Value \\
\hline No. of participants (\%) & $548(100)$ & $142(25.9)$ & $406(74.1)$ & \\
\hline Visit number [mean $\pm \mathrm{SE}]$ & $3.3 \pm 0.1$ & $3.2 \pm 0.1$ & $3.4 \pm 0.1$ & 0.0847 \\
\hline Mean age (min-max), year & $70.8(60-87)$ & $71.4(62-84)$ & $70.5(60-87)$ & 0.0653 \\
\hline Height [mean \pm SE $(\mathrm{cm})]$ & $154.7 \pm 0.3$ & $164.3 \pm 0.4$ & $151.3 \pm 0.3$ & $<.0001$ \\
\hline Weight [mean \pm SE $(\mathrm{Kg})]$ & $59.4 \pm 0.4$ & $65.8 \pm 0.8$ & $57.1 \pm 0.4$ & $<.0001$ \\
\hline \multicolumn{5}{|l|}{ BMI (kg/m²), no. (\%) } \\
\hline$\geq 25$ & $242(44.2)$ & $56(39.4)$ & $186(45.8)$ & \multirow[t]{3}{*}{0.1485} \\
\hline $23 \sim<25$ & $169(30.8)$ & $42(29.6)$ & $127(31.3)$ & \\
\hline$<23$ & $137(25.0)$ & $44(31.0)$ & $93(22.9)$ & \\
\hline No. of current smokers (\%) & $30(5.5)$ & $29(20.4)$ & $1(0.2)$ & $<.0001$ \\
\hline No. of drinker (\%) & $121(22.1)$ & $78(54.9)$ & $43(10.6)$ & $<.0001$ \\
\hline Exercise, no. of yes (\%) & 337 (61.5) & $88(62.0)$ & $249(61.3)$ & 0.9260 \\
\hline
\end{tabular}

evaluation for intra- and inter-individual variations of BPA and MDA levels, ICC of BPA was 0.11 and that of MDA was 0.07 . The means for $\mathrm{PM}_{10}$ on lag day 2 of the health examination and temperature and dew point on the day were $41.3 \mu \mathrm{gg} / \mathrm{m}^{3}, \quad 16.8{ }^{\circ} \mathrm{C}$, and $6.0{ }^{\circ} \mathrm{C}$, respectively.

Twenty-one genotyped polymorphisms of COX2, EPHX1, HSP70-hom, PON1, eNOS, CAT, DRD2, SOD2, and $M P O$ are listed in Table 3 . The call rate of twenty polymorphisms, except rs662, was high with a minimum of $98.7 \%$ (93.5\% for rs662), and all replicated genotyping showed identical results with an accuracy of $100 \%$ (Table 3). When we tested for the Hardy-Weinberg equilibrium (HWE) of each polymorphism with genotype frequency, the study participants were in HWE for twenty polymorphisms, except rs2227956 $(p<0.05$ for rs2227956 and $p>0.05$ for the other twenty polymorphisms using a $\chi^{2}$ test).

The evaluation of the relation between BPA and MDA levels indicated a strong association for BPA exposure with an increase in MDA level $(\beta=0.18,95 \%$ confidence interval $(\mathrm{CI}): 0.14,0.23$, and $p<.0001)$ regardless of sex (male, $\beta=0.19,95 \%$ CI: 0.09, 0.29, and $p=0.0003$; and female, $\beta=0.18,95 \% \mathrm{CI}: 0.12,0.23$, and $p<.0001$ )

Table 2 Distribution of repeated BPA, MDA, cotinine, $\mathrm{PM}_{10}$, temperature, and dew point

\begin{tabular}{lllllll}
\hline & & & \multicolumn{3}{c}{ Selected percentiles } \\
\cline { 5 - 7 } Chemicals & $\mathrm{n}$ & Mean $(\mathrm{SD})$ & & 25th & 50 th & 75 th \\
\hline BPA $(\mu \mathrm{g} / \mathrm{L})$ & 1625 & $1.2(2.6)$ & 0.4 & 0.7 & 1.2 \\
MDA $(\mu \mathrm{mol} / \mathrm{L})$ & 1637 & $1.9(1.2)$ & 1.1 & 1.7 & 2.4 \\
Cotinine $(\mathrm{mg} / \mathrm{L})$ & 1632 & $274.7(1564.1)$ & 0.5 & 2.1 & 4.5 \\
$\mathrm{PM}_{10}$ on lag day $2\left(\mu \mathrm{g} / \mathrm{m}^{3}\right)$ & 1762 & $41.3(23.6)$ & 26.4 & 36.4 & 52.5 \\
Temperature on the day $\left({ }^{\circ} \mathrm{C}\right)$ & 1818 & $16.8(9.0)$ & 9.8 & 18.0 & 24.9 \\
Dew point on the day $\left({ }^{\circ} \mathrm{C}\right)$ & 1818 & $6.0(10.8)$ & -2.0 & 7.7 & 15.3 \\
\hline
\end{tabular}

(Table 4). To evaluate the relation of BPA with MDA according to the genotype of oxidative stress-related genes, the relation between BPA and MDA was estimated for each genetic polymorphism and was found to be consistent regardless of any genotype of COX2, EPHX1, HSP70-hom, PON1, eNOS, CAT, DRD2, SOD2, and $M P O$ (Table 4). Furthermore, we explored the pattern of dose-response relationship between BPA and MDA levels, but did not find any trend for non-linear relationship between the two.

\section{Discussion}

This study showed a strong association of BPA with MDA, not related with sex or with the genetic polymorphisms of nine oxidative stress-related genes (COX2, EPHX1, HSP70-hom, PON1, eNOS, CAT, DRD2, SOD2, and $M P O)$.

Previous reports on the relation between BPA exposure and oxidative stress have supported the possibility of BPA exposure having an effect on adverse health outcomes through oxidative stress. Previous research reported the in vitro induction of reactive oxygen species by BPA in mouse Neuro2a and GC1 cells [14] and a positive correlation of BPA exposure with urinary level of DNA oxidation marker, 8-hydoxydeoxyguanosine (8-OHdG), in residents living in and around e-waste dismantling facilities of China [17]. Furthermore, a longitudinal panel study for pregnant women found positive associations of BPA exposure with urinary oxidative stress markers, 8-OHdG and isoprostane [15]. However, evidence of the relation between BPA exposure and MDA level was inconclusive. Animal studies for BPA observed an increase in MDA level in the heart, liver, ovary, and renal tissues of Wistar albino rats that had been orally administered a high dose of BPA $(10 \mathrm{mg} /$ $\mathrm{kg} /$ day or $25 \mathrm{mg} / \mathrm{kg} /$ day for durations between 30 days and 60 days) $[10,11,13]$. An increase in oxidative 
Table 3 Genotyped polymorphisms

\begin{tabular}{|c|c|c|c|c|c|c|c|}
\hline Gene & rs no. & HGVS name & Chromosome no. & Position & Amino acid change & Call rate (\%) & Accuracy (\%) \\
\hline \multirow[t]{2}{*}{$\operatorname{cox} 2$} & rs5277 & c.306G > C & 1 & Codon102 & Val102= & 99.8 & 100 \\
\hline & rs3218625 & c. $1759 \mathrm{G}>\mathrm{A}$ & 1 & Codon587 & Gly587Arg & 100 & 100 \\
\hline \multirow[t]{3}{*}{ EPHX1 } & rs3766934 & c. $-5-1409 \mathrm{G}>\mathrm{T}$ & 1 & Intron & - & 99.4 & 100 \\
\hline & rs1051740 & c.337 T>C & 1 & Codon113 & Tyr113His & 99.6 & 100 \\
\hline & rs2234922 & $c .416 \mathrm{~A}>\mathrm{G}$ & 1 & Codon139 & His139Arg & 98.7 & 100 \\
\hline \multirow[t]{2}{*}{ HSP70-hom } & rs2227956 & c. $1478 C>T$ & 6 & Codon493 & Met493Thr & 99.1 & 100 \\
\hline & rs2075800 & c. $1804 G>A$ & 6 & Codon602 & Glu602Lys & 99.5 & 100 \\
\hline \multirow[t]{3}{*}{ PON1 } & rs854560 & c. $163 \mathrm{~T}>\mathrm{A}$ & 7 & Codon55 & Leu55Met & 99.5 & 100 \\
\hline & rs13306698 & $c .478 \mathrm{~A}>\mathrm{G}$ & 7 & Codon 160 & Arg160Gly & 99.8 & 100 \\
\hline & rs662 & c. $575 A>G$ & 7 & Codon192 & Gln192Arg & 93.5 & 100 \\
\hline \multirow[t]{3}{*}{ eNOS } & rs1799983 & c.894 T> G, & 7 & Codon298 & Asp298Glu & 99.5 & 100 \\
\hline & rs2853796 & c. $1821-62 G>T$ & 7 & Intron & - & 99.5 & 100 \\
\hline & rs7830 & $c .3106+11 G>T$ & 7 & Intron & - & 99.5 & 100 \\
\hline \multirow[t]{2}{*}{ CAT } & rs769218 & c.67-60G > A & 11 & Intron & - & 100 & 100 \\
\hline & rs769217 & c. $1167 C>T$ & 11 & Codon389 & Asp389= & 98.7 & 100 \\
\hline DRD2 & rs1800497 & $c .2137 G>A$ & 11 & Codon713 & Glu713Lys & 99.6 & 100 \\
\hline \multirow[t]{3}{*}{ SOD2 } & rs4880 & C. $47 \mathrm{~T}>\mathrm{C}$ & 16 & Codon16 & Val16Ala & 99.2 & 100 \\
\hline & rs2758331 & $c .523+816 G>T$ & 16 & Intron & - & 99.6 & 100 \\
\hline & rs5746136 & c. ${ }^{*} 441 \mathrm{G}>\mathrm{A}$ & 16 & Downstream & - & 99.8 & 100 \\
\hline \multirow[t]{2}{*}{ MPO } & rs7208693 & C.157G > T & 17 & Codon53 & Val53Phe & 99.3 & 100 \\
\hline & rs2071409 & c. $2031-6 A>C$ & 17 & Intron & - & 99.5 & 100 \\
\hline
\end{tabular}

stress biomarkers due to BPA exposure was observed in several epidemiologic studies as well. Oxidative stress markers, such as 8-OHdG, white blood cell count, and C-reactive protein, as well as MDA increased in postmenopausal women exposed to BPA, even though the phenomenon was not shown in men and in premenopausal women [16]. However, in a cross-sectional study for adults, BPA was not associated with MDA and 8-OHdG levels after adjusting for covariates affecting oxidative stress [12]. Although BPA was found to affect oxidative stress levels in animals and in older females, a longitudinal panel study found no evidence of a change in lipid peroxidation by BPA exposure. Therefore, the present study estimated the effect of real-time BPA exposure on MDA level, and the results indicate a statistically significant increase in the MDA level related to the BPA exposure, indicating that exposure to BPA at low levels in the environment might be able to cause oxidative damage in elderly individuals, resulting in the development of oxidative stress-related diseases.

In the present study, we tried to estimate the difference of the effect that BPA exposure had on MDA level by sex and genetic polymorphisms of oxidative stressrelated genes (COX2, EPHX1, HSP70-hom, PON1, eNOS, $C A T, D R D 2$, SOD2, and $M P O$ ) because the effect of BPA exposure on adverse health outcomes related to oxidative stress was found to be different depending on sex or genetic polymorphisms of oxidative stress-related genes $[9,16]$. However, we did not find any difference on the effect of BPA exposure on MDA level by sex and by the genetic polymorphisms stated above. BPA is a nonpersistent chemical with a short biological half-life $<6 \mathrm{~h}$, and the oxidative stress that increases due to BPA exposure might be quickly repaired by defense systems in the body [14]. We evaluated the short-term effects of the changes in BPA exposure on MDA level and found no difference on the effect of BPA exposure on MDA level by sex and the tested genetic polymorphisms, which may be due to a momentary effect of BPA on the MDA level made before the defense system of the body becomes active. However, humans are ubiquitously exposed to BPA, and chronic exposure might have an effect on various adverse health outcomes through the continuous accumulation of oxidative stress. Therefore, improving antioxidant defenses, such as with antioxidant supplementation, and regulating BPA exposure in the elderly population could potentially prevent oxidative stress resulting in oxidative stress-related diseases.

In the present study, ICC of BPA was 0.11 while that of MDA was 0.07, indicating that MDA was more changeable than BPA for each individual even though 
Table 4 The relation of BPA with oxidative stress by genotypes of oxidative stress-related genes

\begin{tabular}{|c|c|c|c|c|c|c|c|c|}
\hline & & & $\mathrm{N}$ & Observation & $\beta$ & Lower 95\% Cl & Upper 95\% Cl & $p$-Value \\
\hline Total & & & 517 & 1528 & 0.18 & 0.14 & 0.23 & $<.0001$ \\
\hline Male & & & 134 & 365 & 0.19 & 0.09 & 0.29 & 0.0003 \\
\hline Female & & & 383 & 1163 & 0.18 & 0.12 & 0.23 & $<.0001$ \\
\hline \multirow[t]{8}{*}{$\operatorname{cox} 2$} & rs5277 & GG & 468 & 1392 & 0.17 & 0.12 & 0.22 & $<.0001$ \\
\hline & & GC & 47 & 131 & 0.26 & 0.13 & 0.38 & 0.0001 \\
\hline & & $\mathrm{CC}$ & 1 & 3 & - & - & - & - \\
\hline & & $G C+C C$ & 48 & 134 & 0.26 & 0.13 & 0.38 & 0.0001 \\
\hline & rs3218625 & GG & 500 & 1480 & 0.18 & 0.14 & 0.23 & $<.0001$ \\
\hline & & GA & 17 & 48 & 0.19 & -0.04 & 0.42 & 0.1031 \\
\hline & & AA & 0 & 0 & - & - & - & - \\
\hline & & $\mathrm{GA}+\mathrm{AA}$ & 17 & 48 & 0.19 & -0.04 & 0.42 & 0.1031 \\
\hline \multirow[t]{11}{*}{ EPHX1 } & rs3766934 & GG & 329 & 996 & 0.17 & 0.12 & 0.23 & $<.0001$ \\
\hline & & GT & 164 & 472 & 0.20 & 0.11 & 0.29 & $<.0001$ \\
\hline & & $\pi$ & 22 & 53 & 0.22 & -0.02 & 0.46 & 0.0667 \\
\hline & & $\mathrm{GT}+\mathrm{TT}$ & 186 & 525 & 0.20 & 0.12 & 0.28 & $<.0001$ \\
\hline & rs1051740 & $\pi$ & 172 & 501 & 0.16 & 0.08 & 0.24 & 0.0001 \\
\hline & & $\mathrm{TC}$ & 258 & 768 & 0.19 & 0.12 & 0.25 & $<.0001$ \\
\hline & & CC & 83 & 250 & 0.22 & 0.10 & 0.33 & 0.0003 \\
\hline & rs2234922 & AA & 380 & 1129 & 0.18 & 0.13 & 0.24 & $<.0001$ \\
\hline & & AG & 125 & 365 & 0.20 & 0.12 & 0.29 & $<.0001$ \\
\hline & & GG & 4 & 12 & 0.93 & -3.41 & 5.27 & 0.4539 \\
\hline & & $A G+G G$ & 129 & 377 & 0.20 & 0.12 & 0.29 & $<.0001$ \\
\hline \multirow[t]{7}{*}{ HSP70-hom } & rs2227956 & $\pi$ & 408 & 1202 & 0.18 & 0.13 & 0.23 & $<.0001$ \\
\hline & & $\mathrm{TC}$ & 103 & 310 & 0.18 & 0.05 & 0.31 & 0.0084 \\
\hline & & $\mathrm{CC}$ & 1 & 2 & - & - & - & - \\
\hline & & $\mathrm{TC}+\mathrm{CC}$ & 104 & 312 & 0.18 & 0.05 & 0.31 & 0.0061 \\
\hline & rs2075800 & GG & 181 & 541 & 0.20 & 0.12 & 0.28 & $<.0001$ \\
\hline & & GA & 242 & 718 & 0.14 & 0.07 & 0.21 & $<.0001$ \\
\hline & & AA & 91 & 261 & 0.22 & 0.12 & 0.33 & $<.0001$ \\
\hline \multirow[t]{11}{*}{ PON1 } & rs854560 & $\pi$ & 455 & 1342 & 0.19 & 0.14 & 0.23 & $<.0001$ \\
\hline & & TA & 57 & 174 & 0.13 & -0.02 & 0.28 & 0.0783 \\
\hline & & AA & 2 & 4 & - & - & - & - \\
\hline & & $\mathrm{TA}+\mathrm{AA}$ & 59 & 178 & 0.14 & -0.01 & 0.29 & 0.0669 \\
\hline & rs13306698 & AA & 451 & 1328 & 0.19 & 0.15 & 0.24 & $<.0001$ \\
\hline & & $A G$ & 62 & 187 & 0.17 & -0.01 & 0.35 & 0.0687 \\
\hline & & GG & 3 & 9 & - & - & - & - \\
\hline & & $A G+G G$ & 65 & 196 & 0.16 & -0.01 & 0.34 & 0.0662 \\
\hline & rs662 & GG & 211 & 636 & 0.16 & 0.09 & 0.23 & $<.0001$ \\
\hline & & GA & 209 & 597 & 0.20 & 0.11 & 0.28 & $<.0001$ \\
\hline & & $\mathrm{AA}$ & 64 & 193 & 0.24 & 0.13 & 0.36 & $<.0001$ \\
\hline \multirow[t]{4}{*}{ eNOS } & rs1799983 & GG & 441 & 1309 & 0.18 & 0.13 & 0.23 & $<.0001$ \\
\hline & & GT & 71 & 206 & 0.15 & 0.01 & 0.28 & 0.0308 \\
\hline & & $\pi$ & 2 & 7 & - & - & - & - \\
\hline & & $\mathrm{GT}+\mathrm{TT}$ & 73 & 213 & 0.15 & 0.01 & 0.28 & 0.0299 \\
\hline
\end{tabular}


Table 4 The relation of BPA with oxidative stress by genotypes of oxidative stress-related genes (Continued)

\begin{tabular}{|c|c|c|c|c|c|c|c|c|}
\hline & rs2853796 & $\pi$ & 202 & 589 & 0.20 & 0.13 & 0.27 & $<.0001$ \\
\hline & & TG & 241 & 720 & 0.17 & 0.10 & 0.24 & $<.0001$ \\
\hline & & GG & 71 & 210 & 0.15 & 0.02 & 0.28 & 0.0247 \\
\hline & rs7830 & GG & 158 & 453 & 0.23 & 0.14 & 0.31 & $<.0001$ \\
\hline & & GT & 252 & 741 & 0.17 & 0.10 & 0.25 & $<.0001$ \\
\hline & & $T T$ & 105 & 327 & 0.16 & 0.08 & 0.25 & 0.0001 \\
\hline CAT & rs769218 & GG & 171 & 484 & 0.14 & 0.05 & 0.22 & 0.0016 \\
\hline & & GA & 259 & 787 & 0.19 & 0.13 & 0.25 & $<.0001$ \\
\hline & & AA & 86 & 256 & 0.26 & 0.13 & 0.38 & $<.0001$ \\
\hline & rs769217 & CC & 172 & 485 & 0.14 & 0.05 & 0.22 & 0.0016 \\
\hline & & $C T$ & 254 & 772 & 0.19 & 0.13 & 0.26 & $<.0001$ \\
\hline & & $\pi$ & 82 & 246 & 0.25 & 0.12 & 0.38 & 0.0002 \\
\hline DRD2 & rs1800497 & GG & 197 & 583 & 0.19 & 0.11 & 0.26 & $<.0001$ \\
\hline & & GA & 232 & 679 & 0.20 & 0.13 & 0.26 & $<.0001$ \\
\hline & & AA & 86 & 259 & 0.15 & 0.02 & 0.28 & 0.0276 \\
\hline SOD2 & rs4880 & $\pi$ & 400 & 1189 & 0.20 & 0.14 & 0.25 & $<.0001$ \\
\hline & & TC & 106 & 306 & 0.12 & 0.00 & 0.23 & 0.0430 \\
\hline & & CC & 6 & 20 & 0.66 & -0.04 & 1.35 & 0.0624 \\
\hline & & $\mathrm{TC}+\mathrm{CC}$ & 112 & 326 & 0.15 & 0.04 & 0.26 & 0.0074 \\
\hline & rs2758331 & GG & 406 & 1204 & 0.20 & 0.14 & 0.25 & $<.0001$ \\
\hline & & GT & 103 & 299 & 0.12 & 0.00 & 0.23 & 0.0500 \\
\hline & & $\pi$ & 5 & 17 & 0.64 & -0.29 & 1.56 & 0.1438 \\
\hline & & $\mathrm{GT}+\mathrm{TT}$ & 108 & 316 & 0.15 & 0.04 & 0.26 & 0.0094 \\
\hline & rs5746136 & GG & 167 & 520 & 0.17 & 0.09 & 0.26 & $<.0001$ \\
\hline & & GA & 260 & 750 & 0.16 & 0.09 & 0.22 & $<.0001$ \\
\hline & & AA & 88 & 255 & 0.25 & 0.14 & 0.35 & $<.0001$ \\
\hline MPO & rs7208693 & GG & 408 & 1199 & 0.19 & 0.14 & 0.24 & $<.0001$ \\
\hline & & GT & 97 & 293 & 0.16 & 0.03 & 0.29 & 0.0197 \\
\hline & & $\pi$ & 8 & 24 & - & - & - & - \\
\hline & & $\mathrm{GT}+\mathrm{TT}$ & 105 & 317 & 0.15 & 0.02 & 0.27 & 0.0224 \\
\hline & rs2071409 & AA & 442 & 1300 & 0.19 & 0.13 & 0.24 & $<.0001$ \\
\hline & & $A C$ & 70 & 214 & 0.17 & 0.06 & 0.27 & 0.0016 \\
\hline & & CC & 2 & 5 & - & - & - & - \\
\hline & & $A C+C C$ & 72 & 219 & 0.17 & 0.07 & 0.27 & 0.0011 \\
\hline
\end{tabular}

Adjusted for age, sex, BMl, drinking status, exercise, urinary cotinine level, $\mathrm{PM}_{10}$ on lag day 2, and mean temperature and dew point on the day

intra-individual variation was larger than inter-individual variation for both BPA and MDA. It is explainable based on several points. First, although temporal BPA exposure levels in the same individual were correlated each other in our study because lifestyle habit of each individual is not changed a bit, intra-individual variation of BPA exposure can be still high because half-life of BPA is less than $6 \mathrm{~h}$ and participants may be exposed to BPA through various exposure sources every day. Second, given that MDA is a nonspecific proxy variable, the covariates controlled in our model, such as age, sex,
BMI, drinking status, exercise, urinary cotinine level, $\mathrm{PM}_{10}$ on lag day 2, and mean temperature and dew point on the day, can easily affect MDA level. In fact, all these factors significantly affected MDA level in our analysis. For this reason, we adjusted for these covariates affecting MDA level in the model and found a strong and consistent association of BPA level with MDA level even after adjustment for these covariates.

The major sources of human exposures to BPA are thought to be food and beverage consumption, because BPA is employed to make polycarbonate 
plastics and epoxy resins used in a variety of common consumer products including water pipes and beverage cans [19-21]. A recent study reported that urinary BPA concentrations increased more than 1000\% in subjects who consumed one can of soup per day for 5 days compared to subjects who ate fresh soup [22]. These results indicated that BPA leaches out of source materials in normal condition of use, which can be accelerated if the materials are exposed to high temperatures or acidic environments [23, 24]. Although data on daily BPA intake was not available in the present study, the previous study showing a significant increase of BPA by canned food consumption supports a possibility that food and beverage consumption may be major sources of BPA exposure in Korean elderly frequently consuming canned food.

The strengths of the present study merit further discussion. First, to the best of our knowledge, this is the first longitudinal panel study to investigate the effect of BPA exposure on MDA levels with repeated measurements for BPA and MDA levels for each participant. The design of this panel study allows for the evaluation of the short-term effects on MDA by temporal BPA exposure level. Moreover, this longitudinal study served the subjects as their own controls over the study period. Since our study purpose was to evaluate the acute effect of BPA, a non-persistent chemical with a biological halflife $<6 \mathrm{~h}$ on the MDA level, we used a mixed effect model to evaluate the short-term effects of the changes in BPA exposure levels on MDA level. However, the effect of chronic BPA exposure on oxidative stress should be further studied in the future.

Our study had limitations as well. We recruited subjects aged 60 years or older. If age modifies the effect of BPA on the MDA level, our results may not be generalized to a younger population. In addition, we did not consider other environmental exposure that the participants may be coexposed to during the present study, affecting MDA levels, even though $\mathrm{PM}_{10}$ and meteorological factors were controlled in the models. Since other forms of environmental exposure could also be associated with oxidative stress, the combined effect of multiple exposure factors inducing oxidative stress should be further studied.

\section{Conclusions}

Overall, short-term exposure to BPA was significantly associated with MDA, an oxidative stress biomarker in the elderly. The association between BPA exposure and MDA level was found regardless of sex and any genotype of nine tested oxidative stress-related genes, indicating the strong association of BPA with MDA levels. These findings shed new light to understand physiological mechanism on the development of a variety of diseases by BPA.

\begin{abstract}
Abbreviations
8-OHdG: 8-Hydoxydeoxyguanosine; BMl: Body mass index; BPA: Bisphenol A; CAT: Catalase; Cl: Confidence interval; COX2: Cyclooxygenase 2;

DRD2: Dopamine receptor D2; eNOS: Endothelial nitric oxide synthase;

EPHX1: Epoxidehydrolase 1; HSP70-hom: Heat shock protein 70-hom;

HWE: Hardy-Weinberg equilibrium; ICC: Intra-class correlation coefficient;

LOD: Limit of detection; MDA: Malondialdehyde; MPO: Myeloperoxidase;

$\mathrm{PM}_{10}$ : Particulate matter less than $10 \mu \mathrm{m}$; PON1: Paraoxonase 1; SOD2: Superoxide dismutase 2
\end{abstract}

\section{Acknowledgements}

We thank Yu-Mi Choi for assisting with data collection and genotyping.

\section{Funding}

This study was supported by the Ministry of Environment (900-20150043) and by the Basic Science Research Program through the National Research Foundation of Korea (NRF) funded by the Ministry of Science, ICT and Future Planning (2013R1A1A3A04004612), Republic of Korea. The funders had no role in the study design, data collection and analysis, decision to publish, or preparation of the manuscript.

\section{Availability of data and materials}

Supporting data cannot be shared openly due to ethical concerns and data use agreements.

\section{Authors' contributions}

JHK and $\mathrm{YCH}$ designed the study, collected and analyzed the data, and wrote the manuscript. All authors approved the version to be published.

\section{Competing interests}

The authors declare that they have no competing interests.

\section{Consent for publication}

Not applicable.

\section{Ethics approval and consent to participate}

All participants submitted written statements of informed consent, and the Institutional Review Board at Seoul National University Hospital approved the study protocol (IRB no. H-0804-045-241). This study performed in accordance with the Declaration of Helsinki.

\section{Author details}

${ }^{1}$ Department of Integrative Bioscience \& Biotechnology, Sejong University, 209 Neungdong-ro, Gwangjin-gu, Seoul, Republic of Korea. ${ }^{2}$ Department of Preventive Medicine, Seoul National University College of Medicine, 28 Yongon-dong, Chongno-gu, Seoul, Republic of Korea. ${ }^{3}$ Institute of Environmental Medicine, Seoul National University Medical Research Center, 28 Yongon-dong, Chongno-gu, Seoul, Republic of Korea.

Received: 13 October 2016 Accepted: 14 February 2017 Published online: 15 February 2017

\section{References}

1. Vandenberg LN, Hauser R, Marcus M, Olea N, Welshons W. Human exposure to bisphenol A (BPA). Reprod Toxicol. 2007;24:139-77.

2. Howdeshell KL, Hotchkiss AK, Thayer KA, Vandenbergh JG, vom Saal FS. Exposure to bisphenol A advances puberty. Nature. 1999;401:763-4.

3. Newbold RR, Jefferson WN, Padilla-Banks E. Long-term adverse effects of neonatal exposure to bisphenol $\mathrm{A}$ on the murine female reproductive tract. Reprod Toxicol. 2007;24:253-8.

4. Timms BG, Howdeshell KL, Barton L, Bradley S, Richter CA, vom Saal FS. Estrogenic chemicals in plastic and oral contraceptives disrupt development of the fetal mouse prostate and urethra. Proc Natl Acad Sci USA. 2005;102: 7014-9.

5. Korkmaz A, Ahbab MA, Kolankaya D, Barlas N. Influence of vitamin C on bisphenol $A$, nonylphenol and octylphenol induced oxidative damages in liver of male rats. Food Chem Toxicol. 2010;48:2865-71.

6. Lang IA, Galloway TS, Scarlett A, Henley WE, Depledge M, Wallace RB, et al. Association of urinary bisphenol A concentration with medical disorders and laboratory abnormalities in adults. JAMA. 2008;300:1303-10. 
7. Lee MR, Park H, Bae S, Lim YH, Kim JH, Cho SH, et al. Urinary bisphenol A concentrations are associated with abnormal liver function in the elderly: a repeated panel study. J Epidemiol Community Health. 2014;68:312-7.

8. Hassan ZK, Elobeid MA, Virk P, Omer SA, ElAmin M, Daghestani MH, et al. Bisphenol A induces hepatotoxicity through oxidative stress in rat model. Oxid Med Cell Longev. 2012;2012:194829.

9. Kim JH, Lee MR, Hong YC. Modification of the association of bisphenol A with abnormal liver function by polymorphisms of oxidative stress-related genes. Environ Res. 2016;147:324-30.

10. Aboul Ezz HS, Khadrawy YA, Mourad IM. The effect of bisphenol A on some oxidative stress parameters and acetylcholinesterase activity in the heart of male albino rats. Cytotechnology. 2015;67:145-55.

11. Avci B, Bahadir A, Tuncel OK, Bilgici B. Influence of a-tocopherol and alipoic acid on bisphenol-A-induced oxidative damage in liver and ovarian tissue of rats. Toxicol Ind Health. 2016:32:1381-90.

12. Hong YC, Park EY, Park MS, Ko JA, Oh SY, Kim H, et al. Community level exposure to chemicals and oxidative stress in adult population. Toxicol Lett. 2009;184:139-44

13. Korkmaz A, Aydoğan M, Kolankaya D, Barlas N. Vitamin C coadministration augments bisphenol $\mathrm{A}$, nonylphenol, and octylphenol induced oxidative damage on kidney of rats. Environ Toxicol. 2011;26:325-37.

14. Ooe $H$, Taira $T$, Iguchi-Ariga SM, Ariga $\mathrm{H}$. Induction of reactive oxygen species by bisphenol A and abrogation of bisphenol A-induced cell injury by DJ-1. Toxicol Sci. 2005;88:114-26.

15. Watkins DJ, Ferguson KK, Anzalota Del Toro LV, Alshawabkeh AN, Cordero JF, Meeker JD. Associations between urinary phenol and paraben concentrations and markers of oxidative stress and inflammation among pregnant women in Puerto Rico. Int J Hyg Environ Health. 2015;218:212-9.

16. Yang YJ, Hong YC, Oh SY, Park MS, Kim H, Leem JH, et al. Bisphenol A exposure is associated with oxidative stress and inflammation in postmenopausal women. Environ Res. 2009;109:797-801.

17. Zhang T, Xue J, Gao CZ, Qiu RL, Li YX, Li X, et al. Urinary concentrations of bisphenols and their association with biomarkers of oxidative stress in people living near e-waste recycling facilities in China. Environ Sci Technol. 2016:50:4045-53.

18. Kim JH, Choi YH, Bae S, Park HY, Hong YC. eNOS gene polymorphisms modify the association of PM(10) with oxidative stress. Toxicol Lett. 2012; 214:263-7.

19. Bushnik T, Haines D, Levallois P, Levesque J, Van Oostdam J, Viau C. Lead and bisphenol A concentrations in the Canadian population. Health Rep. 2010;21:7-18.

20. Hanioka N, Takeda Y, Tanaka-Kagawa T, Hayashi K, Jinno H, Narimatsu S. Interaction of bisphenol A with human UDP-glucuronosyltransferase 1A6 enzyme. Environ Toxicol. 2008;23:407-12.

21. vom Saal FS, Hughes $C$. An extensive new literature concerning low-dose effects of bisphenol A shows the need for a new risk assessment. Environ Health Perspect. 2005;113:926-33.

22. Carwile JL, Ye X, Zhou X, Calafat AM, Michels KB. Canned soup consumption and urinary bisphenol A: a randomized crossover trial. JAMA. 2011;306: 2218-20.

23. Brede C, Fjeldal P, Skjevrak I, Herikstad H. Increased migration levels of bisphenol A from polycarbonate baby bottles after dishwashing, boiling and brushing. Food Addit Contam. 2003;20:684-9.

24. Carwile JL, Luu HT, Bassett LS, Driscoll DA, Yuan C, Chang JY, et al. Polycarbonate bottle use and urinary bisphenol A concentrations. Environ Health Perspect. 2009;117:1368-72.

\section{Submit your next manuscript to BioMed Central and we will help you at every step:}

- We accept pre-submission inquiries

- Our selector tool helps you to find the most relevant journal

- We provide round the clock customer support

- Convenient online submission

- Thorough peer review

- Inclusion in PubMed and all major indexing services

- Maximum visibility for your research

Submit your manuscript at www.biomedcentral.com/submit
Biomed Central 